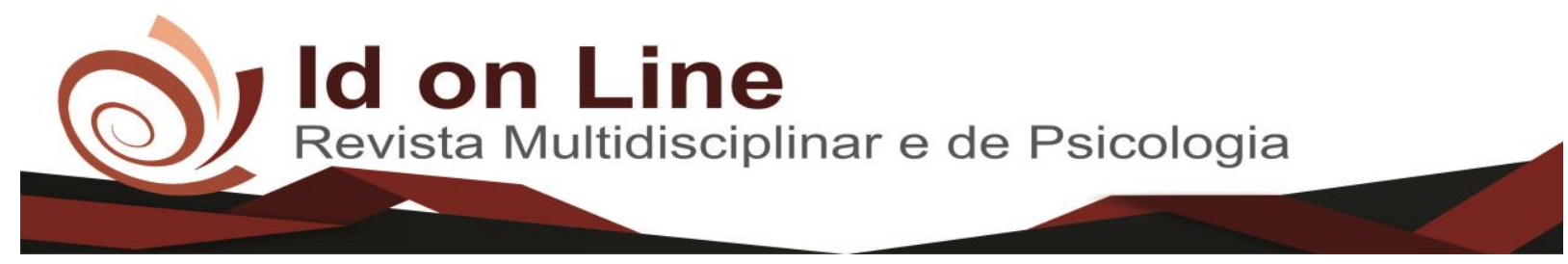

Artigo

\title{
O Impacto das Cores em Crianças na Aquisição de Produtos via E-Commerce
}

\author{
Bruna Martins Angelim ${ }^{1}$; Alyne Leite de Oliveira ${ }^{2}$; Tulio Vidal Rolim ${ }^{3}$;
} Hudson Josino Viana ${ }^{4}$; Maria Patrícia de Alencar ${ }^{5}$

\begin{abstract}
Resumo: Por meio dos efeitos das noções sobre cores como um fator de influência no momento de uma compra, esse desígnio pode ser uma fonte estratégica para os produtores, onde, mediante a era do consumismo em que se captam aspectos emocionais compulsivos, se trabalhados junto da psique, podem obter impactos favoráveis para serem usados como plano de mercado. Nessa conjuntura, o público infantil que nasce inserido na atual era do $e$ commerce possui um poder de indução sobre seus pais, no intuito de convencer estes a comprarem pela internet. O objetivo principal do trabalho consiste em investigar a influência do marketing da psicologia das cores no subconsciente de crianças de 8 a 12 anos que utilizam o e-commerce como forma de induzirem seus pais à compra. O processo foi realizado com 10 crianças residentes no município de Icó-CE, selecionadas através da técnica de snowball. As aplicações utilizadas para simulação de compras foram: Supermarket Boy Party Shopping para os meninos e o Shopping Mall Girl para as meninas, e para análise de dados foi usado o software Iramuteq. Como principais resultados da pesquisa obtiveram-se confirmações de que as cores impactam na influência das crianças aos pais para adquirirem produtos via $e$-commerce. Os jogos lúdicos aplicados detectaram a percepção das crianças voltada às cores; assim como estas foram alvos para as escolhas de determinados produtos no aplicativo e conforme o formulário aplicado, as colorações demonstraram ser critério de escolhas nas compras solicitadas aos pais.
\end{abstract}

Palavras Chave: Marketing. Psicologia das Cores. E-commerce. Público Infantil.

\section{The Impact of Color in Children purchasing products via $E$-Commerce}

\begin{abstract}
Through the effects of notions on colors as a factor of influence at the moment of a purchase, this action may be a strategic source for producers, where, through the era of consumerism in which compulsive emotional aspects are captured, if worked with the psyche, can get favorable impacts to be used as a market plan. At this juncture, the children's public that is born inserted in the current of e-commerce has a power of induction over their parents, in order to convince them to buy online. The main objective of the study is to investigate the marketing influence of color psychology on the subconscious of children from 8 to 12 years that use e-commerce as a way to induce their parents to buy. O process was carried out with 10 children living in the municipality of Icó-CE, selected through the snowball technique. The applications used to simulate purchases were: Supermarket Boy Party Shopping for the boys and the Shopping Mall Girl for the girls, and for data analysis, Iramuteq software was used. As main results of the survey, have confirmed that the colors impact on the children on the parents to purchase products via e-commerce. The applied games detected children's perception of colors; as these were targets for the choices of certain on the app products and according to the form applied, the colorations showed to be criteria of shopping choices parents.
\end{abstract}

Keywords: Marketing. Psychology of Colors. E-commerce. Children's Public.

\footnotetext{
${ }^{1}$ Graduanda do Curso de Administração da Faculdade Vale do Salgado/FVS-bruna.angelim10@gmail.com

${ }^{2}$ Especialista em Logística Empresarial, Orientadora da Graduação e Pós-Graduação da Faculdade Vale do Salgado/FVS e UniLeão, membro do Comitê de Ética em Pesquisa - alyneleite@leaosmpaio.edu.br

${ }^{3}$ Especialista em Engenharia de Software, Mestrando em Ciência da Computação (UFC) - tuliovr@alu.ufc.br

${ }^{4}$ Especialista em controladoria e auditoria, professor de Marketing da Faculdade Vale do Salgado/FVS e coordenador do curso técnico em Administração da Escola Profissional Francisca de Albuquerque Moura/EPFAM-hudson.josino@gmail.com ${ }^{5}$ Graduada em Administração pelo Centro Universitário Doutor Leão Sampaio/UniLeão-patriciaalencar133@ gmail.com

956 Id on Line Rev. Mult. Psic. V.12, N. 40. 2018 - ISSN 1981-1179 Edição eletrônica em http://idonline.emnuvens.com.br/id
} 


\section{Introdução}

As cores são elementos fundamentais para constituir percepções e sensações em qualquer aspecto da vida; e nas compras, isso não difere. Este aspecto deve ser estudado para seu devido uso de forma correta visto que, estas, são essenciais para promover uma venda, aguçada pelo campo visual, como no conjunto que forma os logotipos das marcas, em razão de ser um fator que ajuda a chamar a atenção dos clientes (AMARAL, GAMA e GUEDES, 2014).

Por meio dos efeitos das noções sobre cores como um fator de influência no momento de uma compra, esse desígnio pode ser uma fonte estratégica para os produtores, onde, mediante a era do consumismo em que se captam aspectos emocionais compulsivos, se trabalhados junto da psique, podem obter impactos favoráveis para serem usados como plano de mercado, visto que estas são fatores que possuem grande influência diretamente na hora das compras. A decisão para aquisição de um determinado produto e a relevância das cores neste, observadas sobre a perspectiva da era atual através do perfil dos clientes, abrange diversos aspectos, principalmente voltados às emoções (BATTISTELLA, COLOMBO e ABREU, 2010).

Partindo deste pressuposto, o público que nasce inserido na era da modernização são expostos à fatos de tecnologia de ponta, e consequentemente, ao fácil acesso de serviços e produtos diversificados e segmentados, propiciados pelo estilo consumista do homem atual. Sendo assim, as crianças, apesar de não possuírem uma concepção formada sobre os aspectos de consumo, e ainda estar em fase de amadurecimento das ideias para definir uma escolha mais assertiva de um produto, conforme critérios de faixa etária, necessidade e classe social, elas são dominantes sobre suas famílias na questão de indução da aquisição dos produtos (CALAZAES e FERMIANO, 2013).

Nessa conjuntura, o público infantil que nasce inserido na atual era do e-commerce possui um poder de indução sobre seus pais, no intuito de convencer estes à comprarem pela internet. Este público é adepto aos produtos tecnológicos e vem adquirindo uma acomodação dentro de casa em favor disso (CLARO, MENCONI e LORETO, 2013). O fator de compreensão incompleta, por partes dos pequenos, acaba não influenciando diretamente no aspecto das crianças serem inseridas neste campo de consumo; e resulta-se em uma constante atualização de imersão destes nas consequências do mundo tecnológico. Diante dessas realidades, como é realizado o manejo de marketing das cores, de forma a contribuir 
positivamente na percepção das crianças, instigando-as sensitivamente a persuadirem os pais para compra de produtos via e-commerce em Icó - CE?

Diante desta problemática, objetivou-se investigar a influência do marketing da psicologia das cores no subconsciente de crianças de 8 a 12 anos que utilizam o e-commerce como forma de induzirem seus pais à compra. Além disso, foram aplicados jogos lúdicos para captação da percepção de crianças a respeito das cores; identificou-se o desígnio das colorações como critério de escolha; foram classificadas as nuanças mais chamativas de acordo com o investigado; demonstrado a importância de um adequado uso do marketing das cores; e fez-se possível a descrição do uso satisfatório dos cambiantes no $e$-commerce.

De acordo com a transcendência que se pode analisar em detrimento do uso de cores trabalhadas no comércio eletrônico sobre clientes infantis, se faz necessário o estudo de aspectos destas que induzem estes consumidores a fazer parte de um mercado, mesmo que de forma indireta. Assim, trabalha-se a relevância social aplicada por este marketing, de forma digital. Desde então, lidar com os novos gostos da sociedade, tendo em vista a percepção psicológica, reproduz vantagens tanto para as empresas quanto para os clientes que consomem dos produtos destas, conforme suas preferências.

Dessa forma, as contribuições do estudo no aspecto pessoal e acadêmico, são desempenhadas pela criação de um elo do pesquisador com parte da sociedade na busca de avaliar necessidades de inovações e entendimentos de conceitos de marketing, nos requisitos contemporâneos do e-commerce que tomam conta do mercado atual, ultrapassando as revogáveis realidades de compras no mercado físico. Com base nisso, o trabalho justifica-se por interligar todo esse cenário ao ângulo sensorial, através das cores, como critérios de escolhas em detrimento de aspectos inovadores, o comércio eletrônico e o consumidor infantil.

\section{Psicologia das Cores no Marketing}

Discorrendo do que Carvalho (2013) declara, a Psicologia das Cores é um termo de enorme relevância, que está em toda parte do cotidiano, e representa significados que envolvem o marketing. Ribeiro (2014) diz que, as cores transmitem percepções para a psique humana e que o aspecto cultural é um dos fatores que influenciam nesta psicologia de característica endomarketing. Conforme com o que se estabelece para cada contexto no quesito cor, é 
importante possuir uma análise para ter o respaldo correto, levando em consideração o segmento, como no caso de todo um layout das empresas (CARVALHO, 2013).

De acordo com Cogan (2013) as cores são um dos pontos que mais chamam atenção dos consumidores, porém, esse fator que é emocional, não se sobrepõe sobre a razão no momento de uma compra. Já Carvalho (2013), aponta que as cores são influenciadoras de fornecedores e clientes onde, há dados significativos que indicam que em $84,7 \%$ dos consumidores, dão prioridade às gradações dos produtos do que qualquer outro item que corresponde a estes; ele também diz que $93 \%$ dos compradores analisam as tonalidades no momento de uma compra, deixando de adquirir o que se deseja caso não tenha a cor predileta.

Carvalho (2013) descreve ainda, percentual que mostram o quão importante é a psicologia das cores no marketing; onde: apenas $1 \%$ das pessoas designa uma decisão de compra pelo sentido do olfato ou audição; $6 \%$ pelo tato; e a grande maioria, com 93\%, usa o critério de escolha pela visão, que é onde entra o uso correto desta psicologia para atração de clientela.

Já para Battistella, Colombo e Abreu (2010), a forma como cada cor pode ser posicionada e atrativa para clientes, varia pelos aspectos culturais e particulares de cada ser; nisso, não se compra cor, a aquisição dos clientes se faz ao produto, porém, a coloração de modo subjetiva é interligada a vários processos de vivências pessoais, mesmo que aliada ao concreto ou abstrato.

Nogueira et al. (2015), Battistella, Colombo e Abreu (2010) e Cogan (2013), afirmam que a imaginação dos compradores aponta as cores como circunstâncias, desejos, e um leque de sentimentos, que como no caso do branco, transmite paz; e que de acordo com o ramo empresarial, se faz necessário o estudo de qual cambiante usar na logo, nos produtos, no estabelecimento; enfim, uma análise de sensações voltadas ao que cada uma impele nas pessoas é que vai determinar o uso de tal. Ainda dizem que as cores são meios de difusão na própria particularidade, onde é repleta de proclamação de sentimentos, ideias e assuntos, possibilitando um elo emocional com quem recebe a propagação. Nisso, a visão cognitiva racional e o modelo emocional envolvem, respectivamente, experiências de avaliações por parte do consumidor sobre informações de marcas e lojas, e instituem impulsos na hora das compras.

Carvalho (2013) apresenta benefícios que as colorações desempenham para as pessoas no seu dia a dia, como o avanço na leitura; no aprender e na compreensão; e ele afirma que as nuanças fazem parte de algumas tipologias, que são elas: as primárias, secundárias, terciárias, 
dentre outras. Retratando o que ele demonstra, na primária, em que confere 3 tons (vermelho, amarelo e azul), o vermelho representa emoções, paixão, estimula e desempenha variadas características que, trazendo para as organizações, a cor vermelha pode ser usada em restaurantes para incitar o desejo de degustação dos clientes; o amarelo, chama a atenção, como em placas de promoções de lojas; o azul em instituições, pois instiga o saber; o verde em marcas de produtos naturais; dentre outras com suas respectivas influências sobre pessoas ao serem usadas por grandes empresas, por meio de instintos no cérebro do consumidor ou consumista.

Já para Battistella, Colombo e Abreu (2010) em cada entretom, se encontram divergentes variáveis onde, todas apresentam exclusividade em seus atributos; sendo assim, determina-se para o vermelho a cor que pode ser vista mais rápida que as demais, pois, se sobressai diante dessas; a laranja comparece ampliação sobre a área pigmentada por ela; o amarelo estabelece atenção; o verde importa esperança; o azul é a cor mais fria; o violeta representa um paralelo de temperamento com suavidade; o magenta resume fé e domínio; o marrom não possui realce; o branco é a mistura de todas as cores; o preto a ausência delas e a cinza é neutro entres as duas últimas citadas.

Batista e Fermiano (2013) articulam que dentre os atrativos de comerciais infantis, as cores chamativas são um dos artifícios usados para conduzir as crianças ao consumo de produtos que são lançados, devido a possibilidade de arquivamento desses fatores estratégicos na memória deste público, pela forma como é vinculada. Sendo assim, o marketing estratégico da psicologia das cores pode ser usado até para os pequenos, visto que estes são grandes adeptos do consumo na atualidade e a publicidade vem investindo muito em produtos infantis mediante esta realidade (BATISTA e FERMIANO, 2013).

Battistella, Colombo e Abreu (2010) asseguram que o design de uma embalagem, onde está incluso sua coloração, muitas vezes, é o único fator diferencial de um produto perante sua concorrência que, por exemplo, possui ingredientes, benefícios e preços parecidos. Sendo assim, a visão da clientela diante um produto, dentre vários parâmetros, passa a ser algo de cuidado para o fabricante delimitar o arranjo do design corretamente, no intuito de ser assertivo em quem for impactar, diante uma variação de fornecedores e marcas (BATTISTELLA, COLOMBO e ABREU, 2010).

\section{Marketing das Cores no E-Commerce}


Sobre a perspectiva de Coelho, Oliveira e Alméri (2013) entender o quão importante se faz atrelar as cores ao pré-requisito de vendas, no campo eletrônico, torna o meio concorrente consequentemente hábil em atender o que o público espera de forma subjetiva, porém inovadora. Critérios voltados para a percepção, relação, diferenciais de competitividades, são os que satisfazem a clientela; pois, atualmente o público não busca apenas um único foco, o que faz com que as empresas busquem seguir as tendências, por meio de veículos informatizados tecnologicamente (COELHO, OLIVEIRA e ALMÉRI, 2013).

Para Amaral, Gama e Guedes (2014), muitas vezes, o valor que a harmonia das cores apresenta ao psicológico, passa despercebido na hora de ajustes destas no campo de vendas, inclusive em sites comerciais, levando em consideração os paradigmas acoplados aos gostos culturais pré-estabelecidos pela sociedade; nisso, gostos ligados à hábitos, costumes étnicos, faixa etária e sexo, influem na escolha de combinações de cores como por exemplo, por crianças, visto que estas também observam as formas daquilo que apreciam, como no caso de produtos.

E de acordo com Ceribeli, Inácio e Felipe (2015), as determinantes: utilitaristas, que é a praticidade associada ao comércio eletrônico; hedonistas, que interligam o prazer durante compras feitas na internet; sociais, onde captam a influência da sociedade sobre o homem ao comprar online; situacionais, meios encontrados nos cenários mercadológicos; e de confiabilidades, que envolvem riscos e benefícios de aquisições via e-commerce; é o que prevalece mediante decisões de consumidores do comércio eletrônico. Aspectos como estes, podem ser diagnosticados como inclusões de escolhas para os produtores do mercado comercial eletrônico, que deve levar em consideração sempre a mudança contínua de composições da psicologia humana (AMARAL, GAMA e GUEDES, 2014).

Claro, Menconi e Loreto (2013) relatam que, procurar atender o público alvo para o perfil de uma empresa no e-commerce, se torna uma tarefa segmentada; porém, pode-se tentar alcançar novos cujos, em geral, mediante o fator de investimento em marketing das cores para alcance representativo de uma parcela de pessoas, conforme critérios estabelecidos e estudados pela psicologia, que são relevantes. Os autores supracitados afirmam ainda que eletrônicos, vestimentas e fatores relacionados ao diferencial do padrão brinquedos, são componentes alvejados pelas crianças em muitos casos; e mediante esta afirmação, o público infantil poderia ser o tipo de perfil visado por uma empresa e-commerce que investe em marketing das cores 
pois, estas possuem interesse nos meios tecnológicos.

Segundo Coelho, Oliveira e Alméri (2013), através do comércio eletrônico os clientes podem comprar sem sair de casa, sentindo-se mais à vontade sem uma inspeção por parte de vendedores, mas por outro lado, há aqueles que preferem um auxílio na hora das compras, havendo assim, uma diferença de preferências por parte dos consumidores. Já para Mendes (2013), os recursos proporcionados pela internet, como o e-commerce, estão inseridos no cotidiano das pessoas como algo banal e atinge mais públicos a cada dia, sem haver grande diferença da loja online para a física, sendo a primeira, de maior praticidade e conforto para a população independente de quem venha atingir.

No entanto Barki, Botelho e Parente (2013), alegam que os serviços físicos atendem mais um determinado público local do que o comércio eletrônico, que não foca, em sua maioria, num campo de pessoas por região, mas sim em um todo, e isso pode ser aproveitado como um diferencial competitivo das lojas concretas. Tendo em vista tal circunstância, o marketing das cores pode ser aplicado no e-commerce como um modo de reverter essa situação sendo paralelo às lojas off-line, atingindo desde a sociedade local quanto um todo, e sendo assim, ele sai em proveito se analisado de forma geral (BARKI, BOTELHO e PARENTE, 2013).

Martins (2013) cita que um consumidor ao entrar em um site de compras, pode fechar um negócio ou simplesmente fechar a página sem comprar nada somente pelo fato da cor ser agradável ou invasiva. Ele ainda assegura que a cor azul traz clareza e é vista de forma positiva pelos consumidores online; e que dentro desta afirmação, percebe-se que geralmente as redes sociais usam de tal cor para que as pessoas retirem o estresse e naveguem de forma tranquila, o que pode ser aproveitado por páginas de vendas. Conforme Martins (2013), a cor laranja por ser atrativa e ocasionar impulso, pode ser usada no e-commerce em um botão de confirmar compras; e dessa forma compreende-se que o marketing das cores agrega valor ao comércio eletrônico.

\section{Crianças como Influenciadores na Conduta de Compras dos Pais}

Em relato ao que afirma Claro, Menconi e Loreto (2013), devido ao progresso da psicologia infantil e à convergência do mercado a mais segmentações; vêm se resultando pesquisas sob a análise de condutas dos consumidores desde a infância. De acordo com Abreu 
e Vasconcellos (2009), crianças dos 8 aos 15 anos possivelmente, podem criar uniões mais intensas com promoções e até dar início à processos de fidelização às marcas, tendo em vista que essa fase é onde há uma autonomia que ultrapassa a da família e estão mais predispostos a reconhecer um novo aspecto exterior aos das vivências do lar, sendo submersos às mídias.

Calazaes e Fermiano (2013) citam que na era do modernismo há uma expansão desenfreada da tecnologia e consequentemente, de mudanças dos hábitos em que se alastrou a geração do consumismo acelerado, que impacta sobre os consumidores infantis. Conforme Claro, Menconi e Loreto (2013) destacam, muitas vezes, as crianças não são motivadas pela estratégia de mercado feito por elementos eletrônicos, mas sim, pela constância que este apresenta; e grande parte deste comércio não visa atingir este público de forma direta. Se sem um trabalho de marketing, pela maioria dos empreendimentos virtuais, voltado especificamente a este público que já nasce inserido neste contexto, o público infantil já participa indiretamente das compras, idealiza-se uma percepção do quanto estes poderiam impactar mais ainda esse campo de forma positiva (CLARO, MENCONI e LORETO, 2013).

Silva e Fermiano (2013) trazem a abordagem de que no marketing existe um mundo real e um fictício para ser promovido às crianças, com a finalidade de persuadi-los e desse modo, ao conseguir, se segue o próximo passo que é o de convencimento das mesmas aos pais. Neste contexto, os públicos infantis são abrangidos pelo racional, social, e o afetivo, possibilitando variações interiores em que, se compra para ter algo e não por precisão sendo adquirido assim, o perfil de consumistas (SILVA e FERMIANO, 2013).

Em conformidade com os autores supracitados, Batista e Fermiano (2013) dizem que, nos dias atuais a merchandising está cada vez mais envolvida às crianças no intuito de instigar estas às compras. Elas acabam decidindo o que os pais devem comprar, exercendo o papel de influenciadores no comportamento destes, e muitas vezes induzem produtos que não são adequados para si, mas palpitam sobre tais, sem conduzir a lógica da despesa final das compras que é arcada pelos seus responsáveis (ABREU e VASCONCELLOS, 2009).

Calazes e Fermiano (2013) declaram que o fator das mulheres exercerem seu papel no mercado de trabalho, infligindo a ausência destas no lar, em conjunto com os efeitos das mídias e tecnologias, em geral, provocaram mudanças estruturais nas famílias, como a influência das crianças nas compras, como um meio de suprir uma ausência humana, quando um produto é adquirido por estes através dos pais.

Contudo, o consumo de tal produto é instigado por promoções, como no caso das que 
possuem brinquedos colecionáveis, onde Abreu e Vasconcellos (2009) dizem que, a forma como é feita a abordagem, em cima de coleções, induz o público infantil a querer todos deste conjunto, visando, por exemplo, o fato de cada compra dá o direito à apenas um brinquedo e a criança precisará conduzir aos pais a comprarem o mesmo produto várias vezes, em um curto intervalo de tempo, na maioria das vezes, para concluir a coletânea.

\section{Metodologia}

O tipo de estudo trata-se de uma pesquisa de natureza aplicada, sendo esta uma investigação que pretende contribuir para a ciência, por meio da prática realizada numa determinada circunstância (GIL, 2017). O objetivo é descritivo e exploratório. Quando o objetivo é de fator descritivo, há um relato de peculiaridades das pessoas que fazem parte do contexto de exame (GIL, 2017). Já o exploratório, possui uma gama de rendimentos acerca do entendimento do assunto, relacionando principalmente o problema a ser investigado (MARCONI e LAKATOS, 2017).

A abordagem da pesquisa é de caráter qualitativo, definida por possuir envolvimento com alguns aspectos, dentre tais, estão: a interpretação de palavras, os fenômenos, sentidos humanos, análises naturalistas, e diagnósticos culturais; assim como outros (MARCONI e LAKATOS, 2017).

Os procedimentos técnicos adotados são a pesquisa em fontes bibliográficas e pesquisa semi-experimental. $\mathrm{O}$ estudo de forma bibliográfica passa por procedentes sequências de métodos na vida de estudantes, onde cabe o entendimento das fundamentações que possuem bases de temas existentes (MOLINA, 2016). Os métodos semi-experimentais possuem traços de curto período de tempo para observação e coleta de dados (VENDA, 2013).

O público de participantes total da pesquisa consistiu em uma amostra de 20 pessoas, onde 10 foram mães e 10 foram crianças. Segmentando esta última categoria, 5 foram meninas, que representam $50 \%$ do sexo feminino deste público infantil, e os outros 5 ou $50 \%$ da amostra foram meninos, categorizando o sexo masculino da pesquisa. Dentre as crianças entrevistadas, 4 possuem Nível Fundamental I, e 6 destas cursam o Nível Fundamental II.

A amostra da pesquisa se constituiu em um público infantil na faixa etária de 8 aos 12 anos, sob aceite dos pais e seguindo as premissas da resolução do Comitê de Ética. De acordo 
com a Redação (2013), é comum crianças na faixa etária de 8 aos 12 anos manusearem dispositivos eletrônicos vinculados à internet, em percentuais consideráveis de preferências à diferentes vias de acesso por dia.

Como outros critérios de inclusão, a pesquisa ressalta que: a) as crianças devem ter influenciado os pais em alguma compra via e-commerce nos últimos 6 meses; $b$ ) que gostem de manusear aparelhos tecnológicos assim como, ter um domínio de no mínimo o básico sobre estes. Já como critérios de exclusão: a) crianças que tenham influenciado os pais em uma compra nos últimos 6 meses, por comércio eletrônico, mas que não gosta de tecnologia; e $b$ ) serem leigos no manejo de ferramentas informatizadas.

Neste meio de direção da pesquisa, o processo foi realizado de forma individual através de uma amostra bola de neve/snowball, sendo assim, um método indutivo, por saturação das informações. A coleta foi realizada no domicílio de cada participante, sendo este transformado em ambiente lúdico, adicionado ao uso de celular de modo que possibilitasse a utilização de aplicativos para as crianças, sendo uma análise aplicável e acessível a elas e sem interrupção do processo durante sua execução, na cidade de Icó - CE.

A pesquisadora compareceu ao local de estudo utilizando, em primeiro momento, um método de coleta por observação, não participante, desempenhado através de jogos lúdicos que consistiram em dois aplicativos simuladores de compras, chamativos por envolver um design realçado, sendo estes: Supermarket Boy Party Shopping, para os meninos, e o Shopping Mall Girl, para as meninas. E em seguida, se fez a coleta de dados através de um formulário semiestruturado aplicado às crianças e aos pais, separadamente, e as entrevistas foram transcritas para possibilitar a análise. Este procedimento do aplicativo buscou divertir as crianças, onde, por meio desta etapa a pesquisadora pôde assimilar quais os possíveis critérios de escolha dos indivíduos à determinada cor no software, com base na contemplação.

Dentre as características dos jogos, ambos foram desenvolvidos para dispositivos móveis (tablets e smartphones) com o sistema operacional android. Os jogos estão disponíveis na loja de aplicações da Google Play ${ }^{56}$. Estes permitem que as crianças se sintam estimuladas ao ato de compras em um ambiente virtual. Os itens disponibilizados nos aplicativos são

\footnotetext{
${ }^{5}$ https://play.google.com/store/apps/details?id=com.kidsfunplus.market.boy.party. shop

${ }^{6} \mathrm{https} / / /$ play.google.com/store/apps/details? id=com.cocoplay.shoppinggirl
} 
similares distinguindo-se entre uma diversidade de cores. Deste modo, as crianças selecionam um item por meio do clique, sendo induzidos pela seleção das cores que mais as atraem.

Figura 1: Aplicativo Super Market Boy. $\quad$ Figura 2: Aplicativo Shopping Mall Girl.

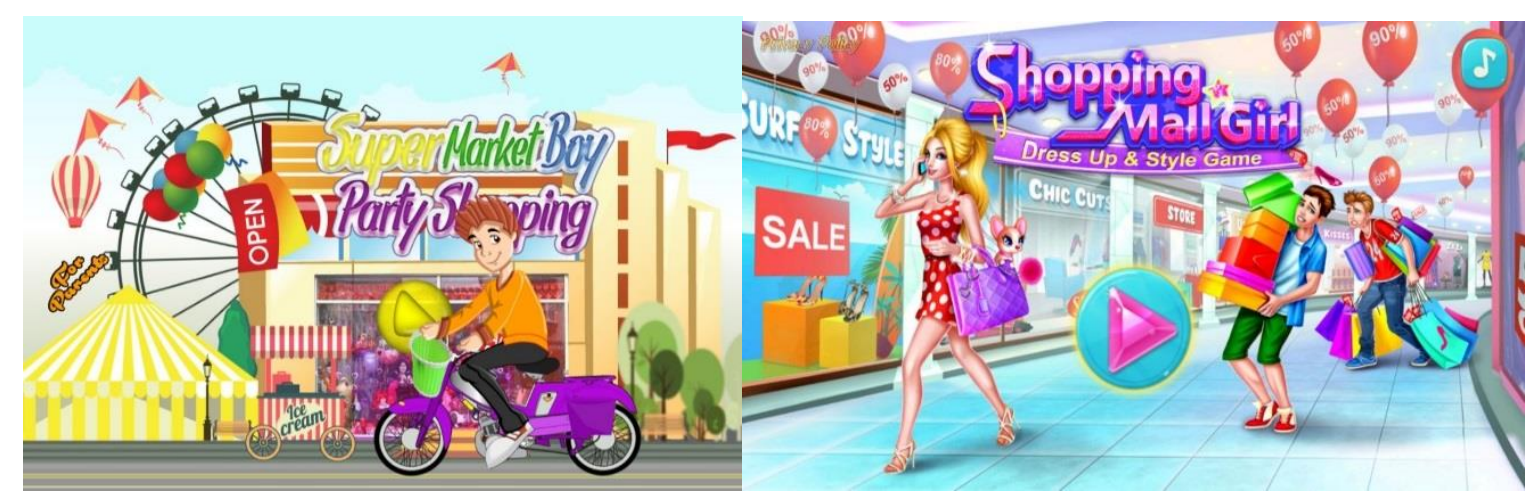

Fonte: Google Play, 2018a.

Fonte: Google Play, 2018b.

O Super Market Boy Party Shopping é um aplicativo que simula um supermercado de compras para festas de aniversário, contendo roupas, tênis, itens de decoração e alimentação bem como outros (GOOGLE PLAY, 2018a). Já o Shopping Mall Girl é um aplicativo de entretenimento que permite a compra de produtos como: roupas, calçados e acessórios para meninas, tudo dentro de um ambiente caracterizado como shopping (GOOGLE PLAY, 2018b).

Dentre as funcionalidades do Shopping Mall Girl encontram-se: $i$ ) compre com a ajuda de uma personal stylist própria; ii) compre em suas lojas favoritas, como Hop Shop, Garota Urbana, Forever \& Ever e outras; iii) vista-se com camisetas, saias, sapatos e acessórios!; e iv) escolha entre toneladas de maquiagens e cosméticos. As Figuras 3 e 4 apresentam algumas das interfaces presentes no aplicativo.

Figura 3: Atividades do Shopping Mall Girl.
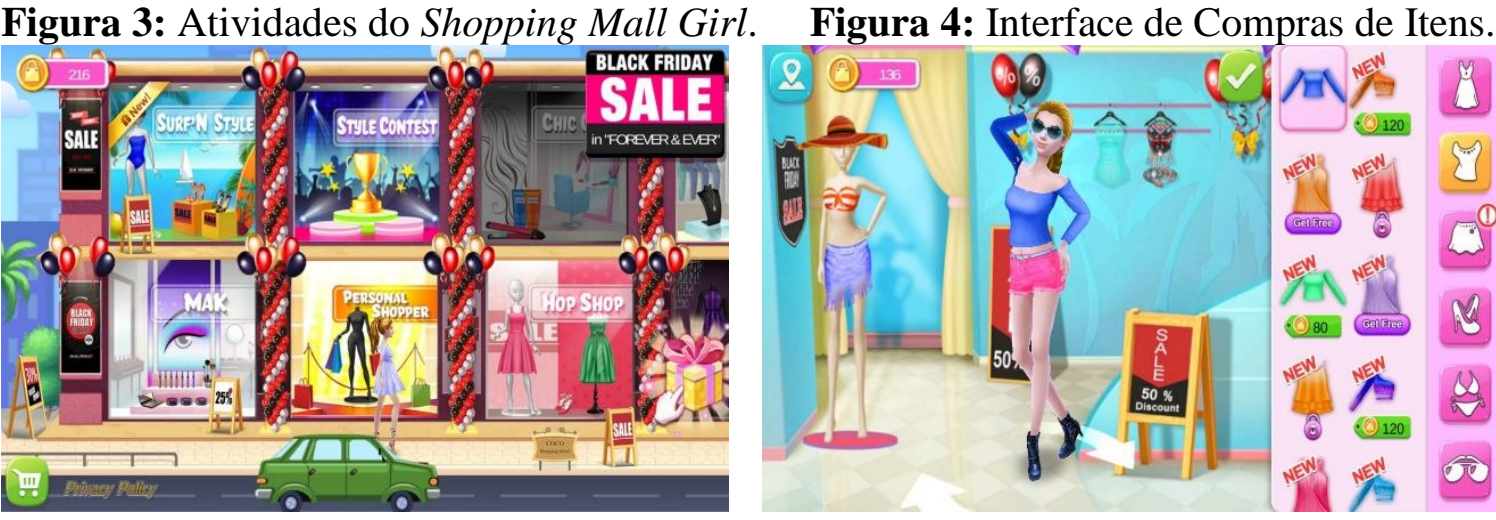

Fonte: Google Play, 2018b.

Fonte: Google Play, 2018b. 
As funcionalidades do Super Market Boy Party Shopping consistem em fornecer aos meninos a compra de itens para festas, dentre essas estão: $i$ ) escolha uma roupa bacana para a festa; ii) encontre um calçado apropriado; iii) organize a festa comprando balões e outros itens de decoração; e $i v)$ compre os itens de alimentação da festa, capriche na escolha do bolo. Algumas das funcionalidades do aplicativo podem ser vistas nas Figuras 5 e 6.

Figura 5: Interface de Compra de Roupas. $\quad$ Figura 6: Interface de Compra de Sapatos.

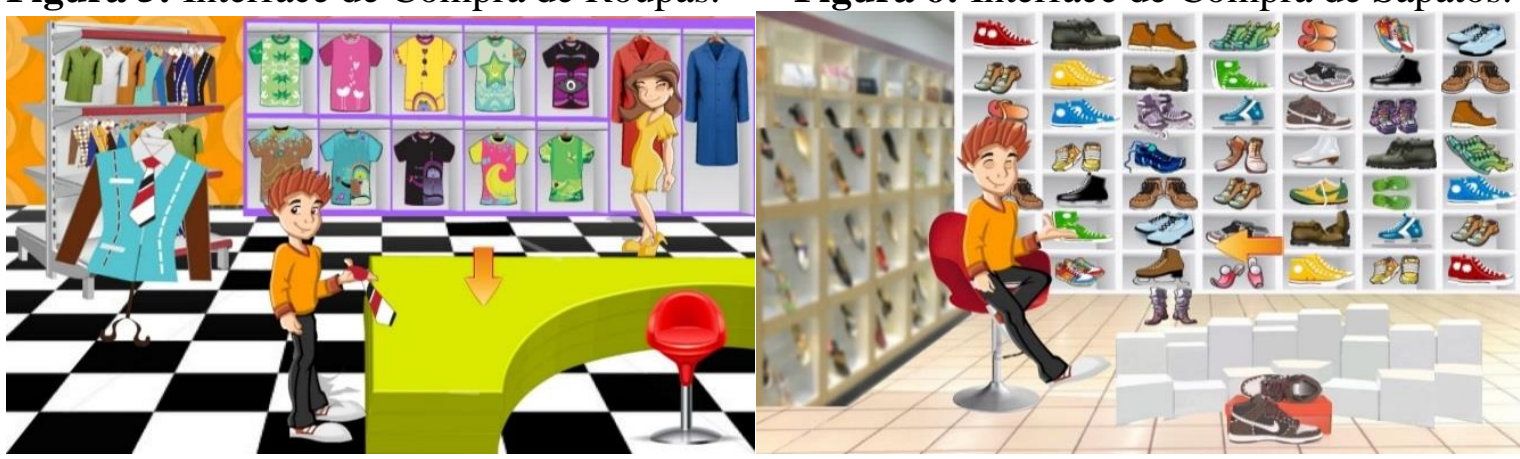

Fonte: Google Play, 2018a.

Fonte: Google Play, 2018a.

Durante o uso, os participantes foram previamente orientados e treinados acerca do uso dos aplicativos. Nesta etapa, os participantes utilizaram o aplicativo por meio de um smartphone tendo a configuração apresentada no Quadro 1.

Quadro 01 - Especificações do dispositivo.

\begin{tabular}{|c|c|c|c|c|}
\hline $\begin{array}{c}\text { Memória } \\
\text { RAM }\end{array}$ & $\begin{array}{c}\text { Memória } \\
\text { ROM }\end{array}$ & Processador & Armazenamento & $\begin{array}{c}\text { Versão } \\
\text { Android }\end{array}$ \\
\hline $2 \mathrm{~GB}$ & $32 \mathrm{~GB}$ & $\begin{array}{c}\text { Octa-core 1.4 GHz Cortex- } \\
\text { A53 (SnapDragon) }\end{array}$ & $32 \mathrm{~GB}$ & $\begin{array}{c}\text { Android } \\
7.1 .1\end{array}$ \\
\hline
\end{tabular}

Fonte: Própria autora, 2018.

Após a coleta, os dados foram analisados através de tabulação e categorizados de forma qualitativa, com base no método de indução; e também foi usada a técnica da análise de conteúdo por meio do software Iramuteq.

Mediante as análises realizadas e diante das falas dos participantes, foram lançados os diálogos e resultados qualitativos colhidos das aplicações no software Iramuteq e obteve-se uma 
filtragem de informações, quando os mesmos foram organizados, em primeiro momento em um banco de dados no Word formando um corpus textual e depois em bloco de notas conforme critérios de ajustes do próprio programa para só assim ser absorvido e gerado os gráficos. Os gráficos produzidos pelo Iramuteq foram: Similitude, Reinert CHD, Reinert AFC e estatísticas gerais.

\section{Análise e Discussão dos Resultados}

Para compor a análise, obteve-se a realização do jogo, e foi aplicado o formulário semiestruturado para as crianças e logo após outro específico para as mães como forma de complementar as percepções obtidas durante a etapa de coleta. A estrutura do formulário para as crianças foi categorizada em 4 perguntas voltadas para o perfil pessoal deste público, 7 perguntas referentes ao aspecto consumidor delas e 3 voltadas ao aplicativo utilizado por elas.

Apurou-se através do formulário para o público infantil, que a cor no qual estes mais perceberam no aplicativo foi o azul, e a menos perceptível foi a cor cinza, por ser uma cor neutra confirmada pela citação de Battistella, Colombo e Abreu (2010). Tal fato da cor azul em ênfase condiz com o autor Martins (2013) que afirma que uma cor agradável, característica da cor azul, aproxima o consumidor ao comércio eletrônico, assim como, é vista de forma positiva pelos consumidores online, os deixando navegar na rede de forma tranquila, podendo ser aproveitado por páginas de vendas, como no caso dos jogos virtuais apresentado às crianças e comprovado pelo formulário.

$\mathrm{Na}$ categoria de segunda cor mais percebida pelas crianças houve um empate entre o amarelo e o preto. Este resultado é confirmado parcialmente conforme o que diz Carvalho (2013) sobre a cor amarela chamar atenção dos consumidores. Um fato curioso descoberto por este estudo é a cor preta em destaque; visto que os autores supracitados no referencial não trazem essa cor como uma nuance perceptiva, mas sim, ressaltam esta, com indiferença. Nisso, há uma nova abordagem para o preto conforme a amostra com essas 10 crianças sendo esta inclusa como convencional. 
Gráfico 1: Cor preferida

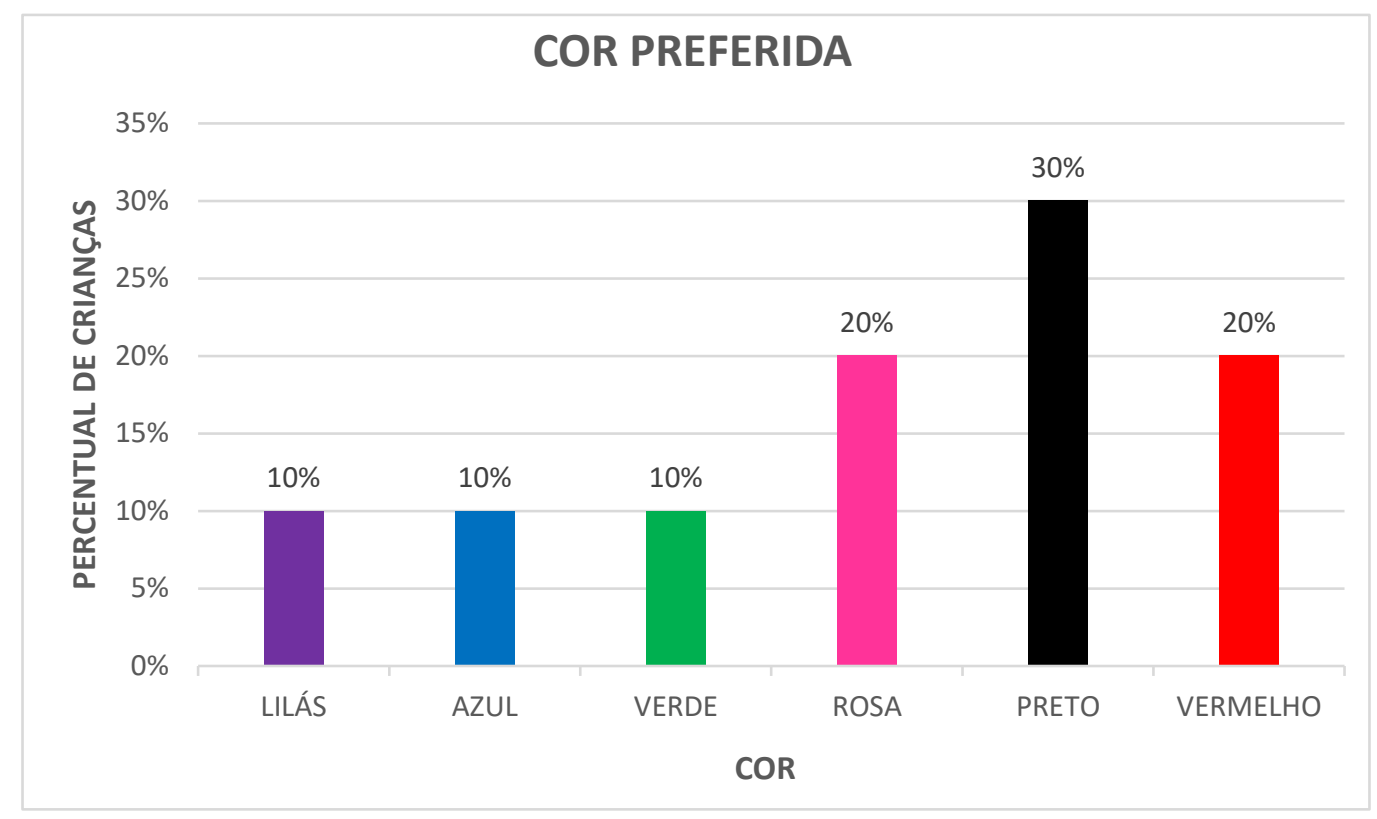

Fonte: Dados da pesquisa (2018).

Analisando a percepção das crianças acerca das cores em conjunto com a cor preferida delas perguntado no formulário semiestruturado, percebe-se que há uma variação entre tais e até mesmo uma contradição em alguns casos. Isso está em acordo com a psicologia das cores que leva o ser humano pelo instinto emocional da percepção cognitiva. O que quer dizer que não adianta alguém ter o azul como predileto mas acabar clicando em um botão amarelo em um jogo, por exemplo, se esta é diagnosticada conforme a psicologia como uma coloração que chama atenção perante as demais.

Em seguida, foi solicitado para as crianças discorrerem sobre algum dos pedidos de compra deles, pela internet, para os pais. Tais falas confirmam o que diz Claro, Menconi e Loreto (2013) ao relatarem que as crianças são motivadas às compras online pela constância deste mercado. Uma das enquetes sobre o perfil das crianças voltado ao consumo pelo comércio eletrônico, procurou entender o que as mesmas acham desse campo vasto que é o e-commerce e outro quesito que o estudo buscou compreender, foi o que elas mais gostam de pedir aos pais para comprarem que está representado no gráfico 2 . 
Gráfico 2: Tipos Itens comprados pelas crianças

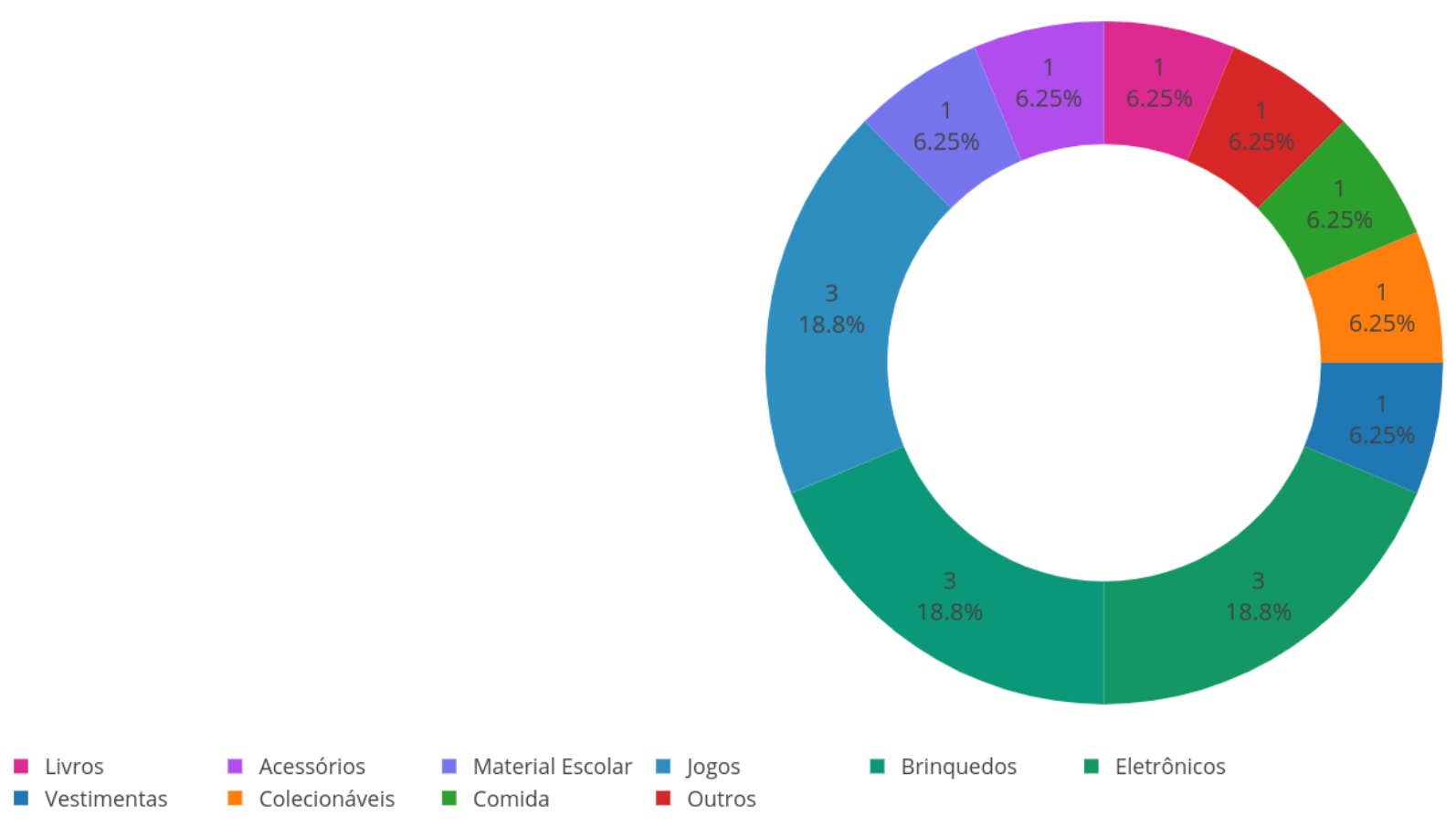

Fonte: Dados da Pesquisa (2018).

De acordo com o formulário tratado no gráfico 2, foi detectado que apenas 03 das 10 crianças apresentaram o item brinquedo como o produto mais pedido para comprar, se igualando aos itens eletrônicos e vestimentas. As demais crianças pedem mais produtos tecnológicos, roupas, jogos, calçados, material escolar e livros do que qualquer outro produto. E isso segundo Claro, Menconi e Loreto (2013) é afirmado, pois eletrônicos, vestimentas e produtos diferenciados de brinquedos são o alvo das crianças nos dias atuais.

Perguntou-se às crianças se elas só compram algo da forma como desejam, em cor, tamanho, formato, etc.; ou se aceitam substituição do produto. Nas respostas, 6 responderam que só aceitam da forma que querem e 4 aceitam um produto substituto. Diante disso, confirmase a citação de Battistella, Colombo e Abreu (2010) que asseguram que o design é um diferencial para ser assertivo ao público. Alguns entrevistados relataram que na internet há uma variedade de opções, facilidade de acesso, produtos com qualidades e as lojas estão sempre atualizadas com novidades, o que chamam a atenção deles para solicitarem aos pais o que querem da forma que desejam conforme afirma a criança 1: “As lojas na internet são cheias de recursos, muitas opções dos produtos... é uma coisa que a gente não precisa sair de casa para 
conseguir, de uma forma simples eu posso comprar produtos do momento e os lançamentos do jeito que eu desejo". Por fim, foi feita uma pergunta às crianças a fim de diagnosticar o que estas acharam do aplicativo usado, se foi satisfatório e o que chamou mais atenção deles no jogo.

De acordo com a fala das mães, percebe-se que grande parte da influência para as crianças fazerem solicitações aos pais de compras pela internet está na atuação dos youtubers sobre este público e nos modelos de vendas baseados em coleções, o que fazem com que as crianças não parem de pedir aos pais o que querem pois há o desejo de ter a coleção completa. Os jogos com indução de moedas para compras são outros passos de introdução do público infantil no consumismo e compra por impulso e desejo. Esses fatos estão comprovados e confirmados respectivamente quando Calazaes e Fermiano (2013) citam sobre a expansão da tecnologia, mudanças de hábitos e consumismo impactados nas crianças; Abreu e Vasconcellos (2009) relatam sobre a forma como é feita a abordagem, em cima de coleções de produtos; e Nogueira et al. (2015), Battistella, Colombo e Abreu (2010) e Cogan (2013), tratam da visão cognitiva emocional e racional de produtos em cima de um público.

Outra pergunta ao segundo público, mães, averigua se estas trabalham e passam muito tempo em casa com seus filhos e obteve-se que 07 delas trabalham e não passam muito tempo com os filhos em casa. As respostas estão de acordo com Calazaes e Fermiano (2013) que alegam que a mulher no mercado de trabalho, as tornam ausentes em casa, e consequentemente os filhos passam a ter um contato maior com mídias tecnológicas.

Complementando o fator acima, também 07 das 10 mães entrevistadas, geralmente acatam aos pedidos dos filhos, o que condiz ao aspecto de se sentirem na necessidade de suprir sua falta de presença em casa, ao realizarem a compra do que as pedem.

Percebe-se que conforme a pesquisa, as mães têm sido cada vez mais assíduas em aceitar os pedidos das crianças para compras na internet. Das entrevistadas, 02 mães adquirem os produtos que os filhos pedem a cada mês; 01 frequentemente aceita; 02 compram a cada data comemorativa; 03 acatam aos pedidos sempre que lhe é solicitado; 01 avalia a solicitação e compra na faixa de 03 em 03 meses e apenas 01, compra no período de 06 a 06 meses, mas nunca ultrapassa essa temporada. Assim pôde-se observar que $100 \%$ das mães da amostra possuem uma visão positiva quanto ao $e$-commerce.

A pergunta seguinte obteve respostas em acordo com Abreu e Vasconcellos (2009), quando este diz que as crianças muitas vezes palpitam em compra de produtos para outras 
pessoas, influenciando a quem vai comprar. Como se observa na fala da Mãe 1 que diz: "Ela já influenciou até mesmo em coisas para casa. Ela fala: 'olha aqui mãe isso fica legal aqui em casa'. E eu sou consumidora assídua da internet, e ela me influencia".

Através da análise de similitude no Iramuteq, que é baseada na teoria de grafos, é possível identificar a aproximação entre palavras por participantes divergentes. Também se deduz a estrutura de construção de textos por meio da conexão de palavras do corpus textual. Segue à apreciação do estudo em questão.

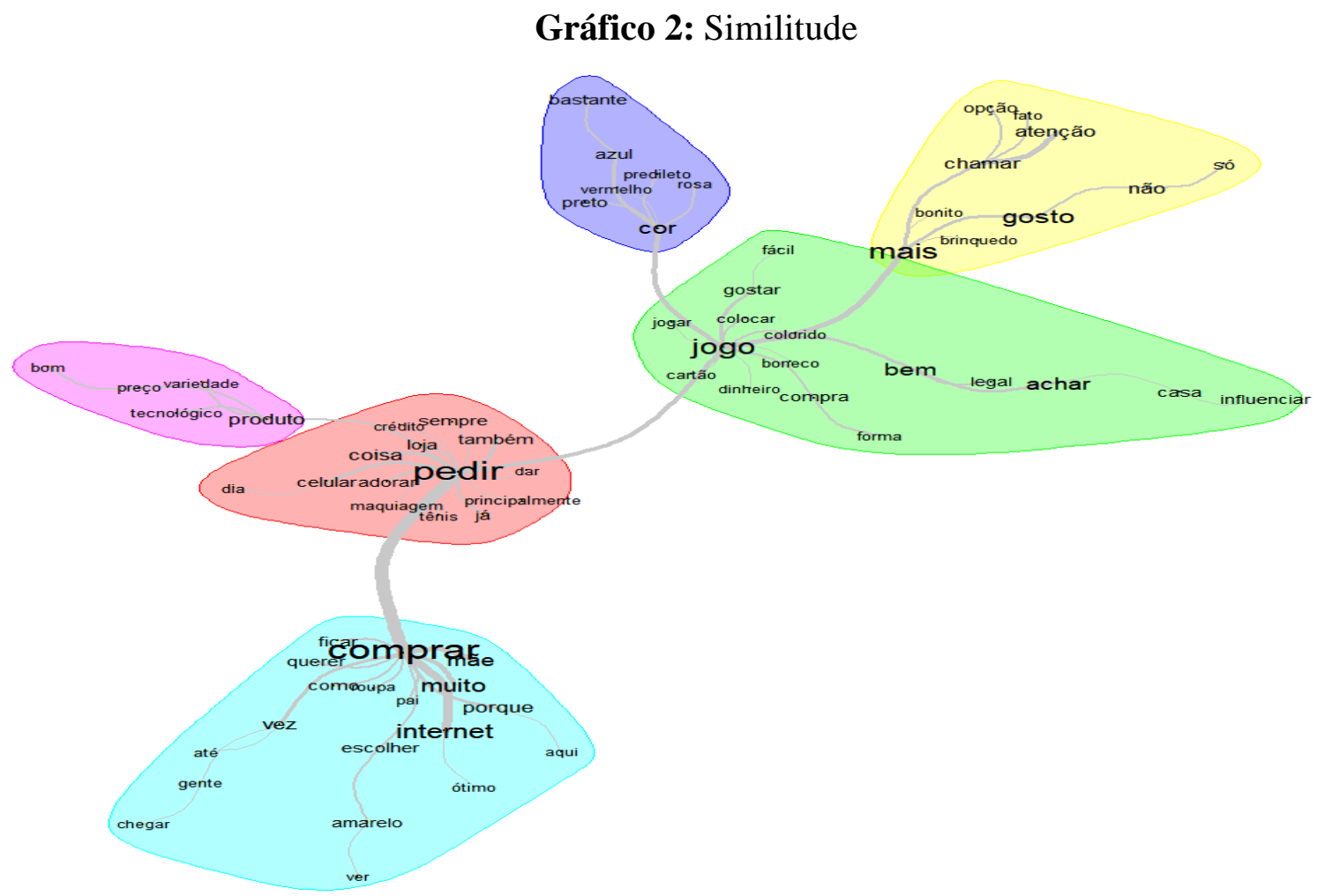

Fonte: Dados do Software Iramuteq (2018).

Observa-se que há algumas palavras que mais se destacam no gráfico: "comprar", "pedir" e "jogo". Assim como destacado na fala da criança 4: "Uma das experiências da compra pela internet que minha mãe sempre aceita meu pedido é de jogos, acho que ela prefere eu em casa jogando do que na rua”. Das palavras que se sobressaem ramificam-se outras que se apresentam importantes: “internet”, "bem”, “mais", "achar", "gosto" e “cor”.

Nas extremidades das ramificações aparece a afinidade entre: "mãe" "muito" e "querer"; que é ressaltada na fala a Mãe 3: "Ela gosta muito de pedir para comprar jogos e casa da Barbie, 
e quando tem um lançamento novo da Barbie ela quer que eu compre. Também acredito que aqueles vídeos que ela assiste nos canais do youtube influencia bastante a ela me pedir as coisas". Em outra ramificação está interligado as palavras "celular" "dar" e "loja"; que pode ser reflexo na fala da Criança 10: "A cor que eu mais gosto é o preto. Na loja do joguinho eu escolhia as roupas e tênis pretos também porque é a cor que peço para minha mãe comprar minhas camisas e ela me dar assim como ela deu meu celular que também é preto..."

Há também uma analogia entre "tecnológico" "preço" e "variedade"; e "influenciar" "dinheiro" e "jogar". Esses aspectos estão sobrepostos nas respectivas falas dos participantes Criança 10: "Elas têm um preço bom e uma variedade de produtos tecnológicos que eu gosto"; e da Mãe 5: "Ela é viciada em um jogo que tem de comprar moedas, e nisso, precisa colocar crédito no celular para conseguir jogar com essas moedas e ela todo dia fica me pedindo crédito por conta desse jogo, e haja dinheiro para isso. Mas eu acabo colocando muitas vezes e eu acho que esses jogos da internet influenciam muito as crianças a comprar e pedir aos pais".

De modo geral, compreende-se que os discursos dos participantes além de estarem em conexão com a literatura exposta, são essenciais ao processo de impacto das cores nas crianças como influência aos pais para o ato das compras via internet.

O corpus geral foi constituído por 15 textos, separados em 1.552 segmentos de textos (ST), com aproveitamento de 9,28 STs (48,16\%). Emergiram 103.47 ocorrências (palavras, formas ou vocábulos), sendo 299 palavras distintas e 144 com uma única ocorrência. O conteúdo analisado foi categorizado em quatro classes: Classe 1, com 28,6\% ST; Classe 2, com 19,6\% ST; Classe 3, com 25\% ST e Classe 4, com 26,8\% ST. Estes dados estão sinalizados no gráfico 3. 
Gráfico 3: Reinert CHD

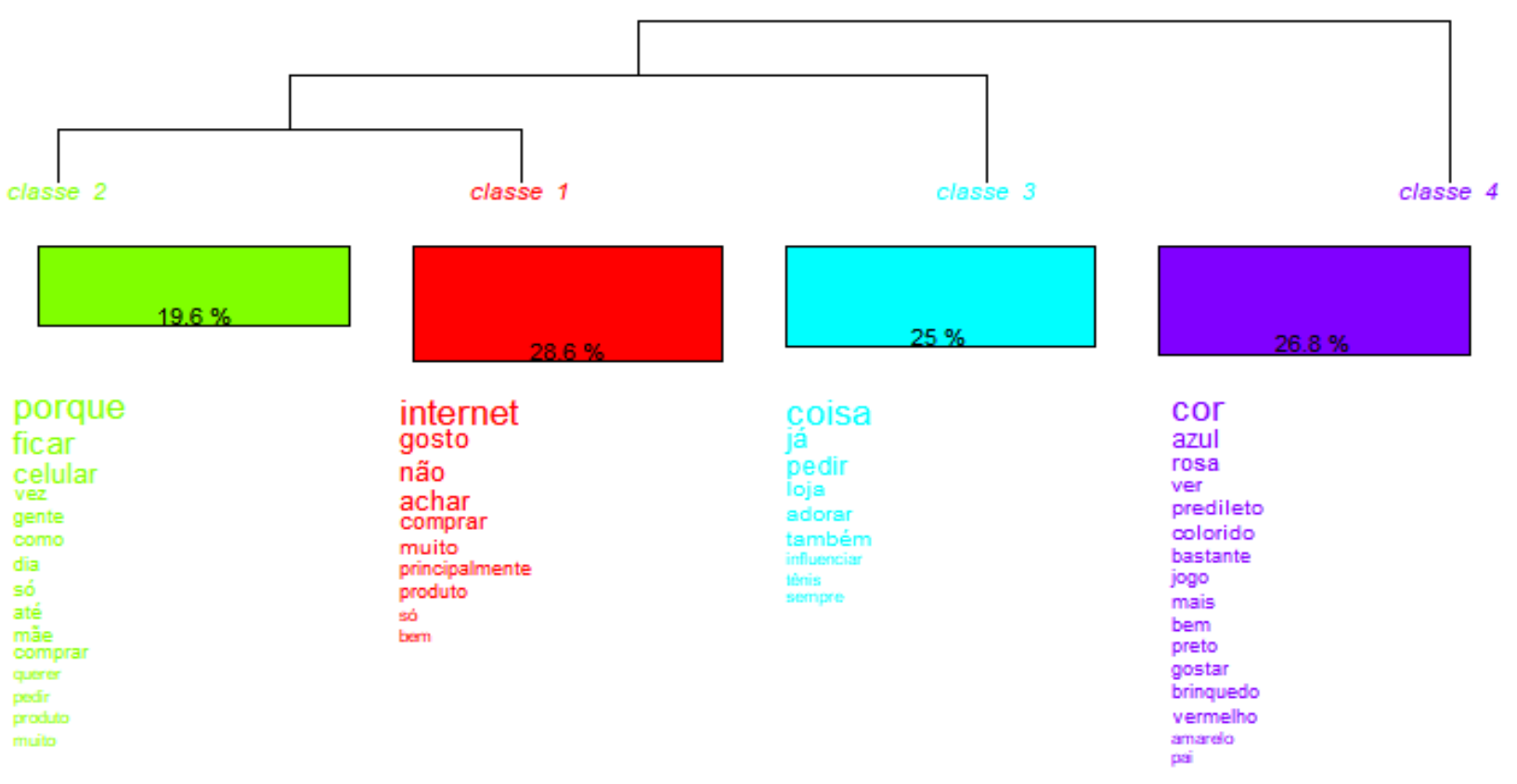

Fonte: Dados do Software Iramuteq (2018).

É importante ressaltar que essas classes se encontram divididas em ramificações do corpus total em análise. O subcorpus "internet", composto pela classe 1 se refere a "gostar desta", ao fator das "compras pela internet" e a opinião do que se acha delas. O subcorpus composto pela classe 2, contém discursos da utilização de ficar com celular; a classe 3 trata de "pedir" e "adorar as lojas"; e a classe 4 apresenta as colorações de modo a realçar mais a cor azul (ver gráfico 3).

Correlacionando o gráfico 3 com o quadro 1 da análise, percebe-se a incidência da cor azul tida como a mais perceptiva durante a aplicação da prática com as crianças no aplicativo, com a apreciação feita pelo software Iramuteq que trouxe esta confirmação na classe 4 . Categoriza-se por meio da classe 1, analisado pelo Iramuteq, que a internet faz parte do quesito compras designadas pelas crianças aos pais.

Se tratando da análise de Reinert AFC - Análise Fatorial por Correspondência; foi possível associar o texto entre palavras, considerando a frequência de incidência de palavras e classes, representadas em um plano cartesiano, conforme o gráfico 4. Observa-se que as palavras de todas as classes se apresentam num segmento que se expande para pontos 
periféricos. Contudo, há várias palavras da classe 1 que ultrapassam os outros quadrantes, principalmente o da classe 2, apresentando junção significativa das classes.

\section{Gráfico 4: Reinert AFC}

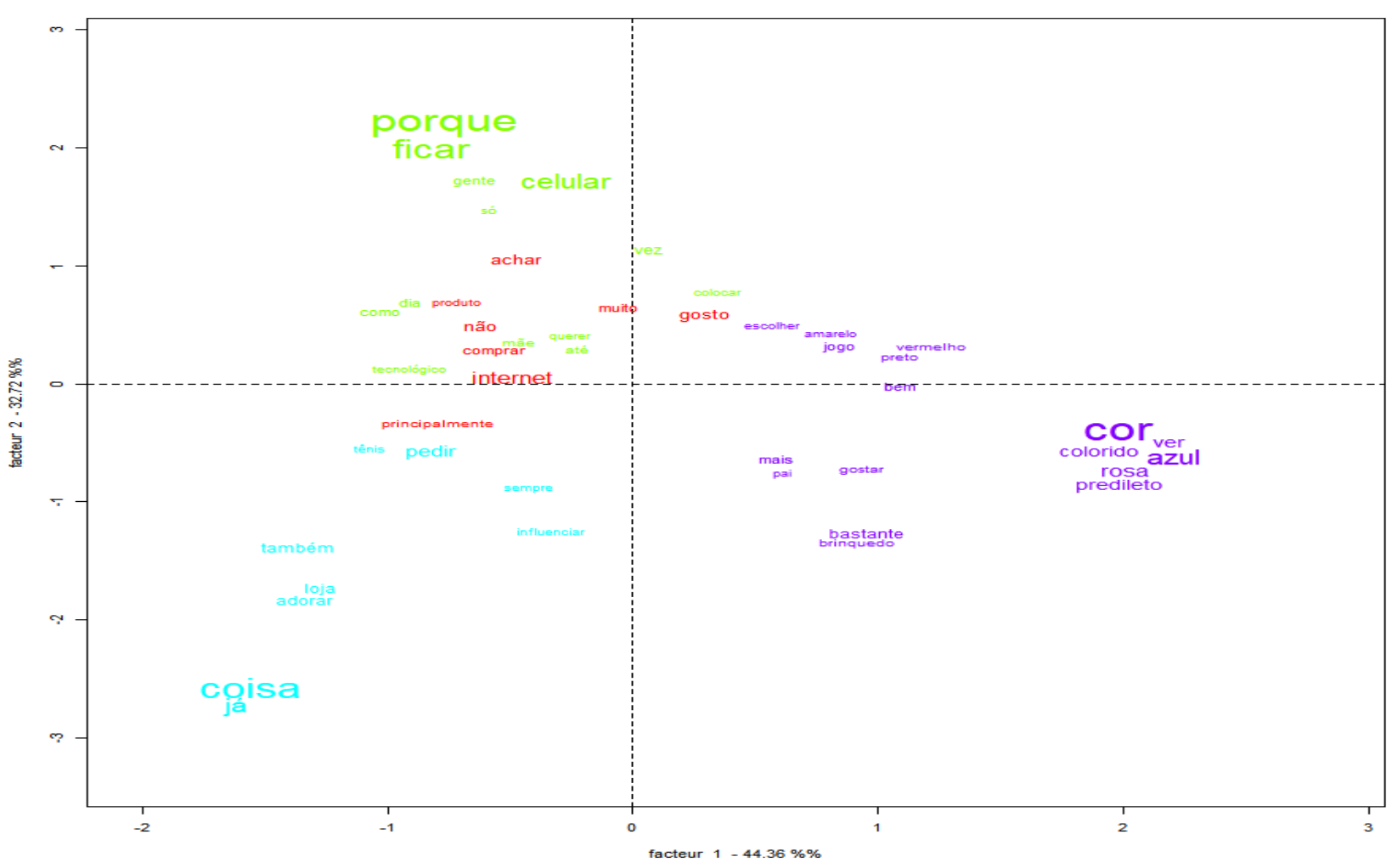

Fonte: Dados do Software Iramuteq, 2018. 
Gráfico 5: Reinert CHD

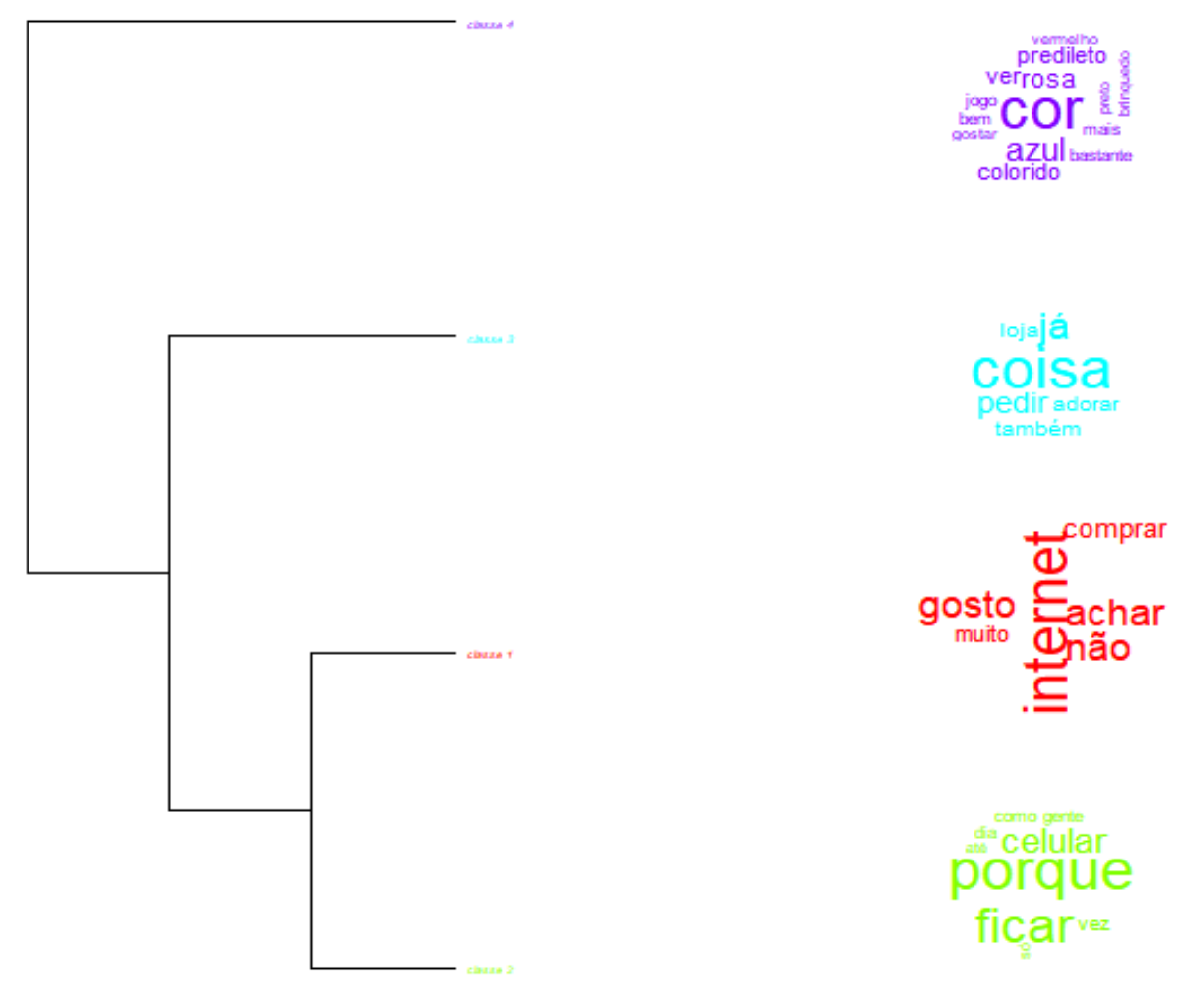

Fonte: Dados do Software Iramuteq, 2018.

Essas citações a respeito do gráfico de Reinert AFC podem ser apreciadas no gráfico 5 que traz uma nuvem de palavras inter-relacionadas entre as classes. Equivalente ao gráfico 4, este traz mais uma confirmação de que celular, um produto tecnológico bastante citado pelas crianças para o momento de uma compra e solicitação aos pais, está incluso na feição de lojas e-commerce, pela internet, como um meio simples de encontrar/achar; conforme pronunciado pelos participantes.

Após as entrevistas às mães e às crianças e depois da análise com o software, percebeuse que as cores e os produtos realmente chamam a atenção do público infantil, e que mediante alguns bloqueios do aplicativo em determinados produtos para uma compra no jogo eram comentados pelas crianças que se fosse desbloqueado escolheriam tal item pela sua cor. Compreendeu-se que tanto o público infantil quanto seus responsáveis são adeques ao $e$ commerce. Foi possível observar também que o jogo usado pelas crianças foi bem aceito levando em consideração que foi um jogo de compras, um alvo da pesquisa. 


\section{Considerações Finais}

Concluindo as duas entrevistas semiestruturadas e a análise de dados, obtiveram-se respostas, alcances e confirmações para as indagações e objetivos a respeito do tema proposto do estudo. Compreende-se que as cores impactam na influência das crianças aos pais para adquirirem produtos via e-commerce. Os jogos lúdicos aplicados detectaram a percepção das crianças voltada às cores; assim como estas foram alvos para as escolhas de determinados produtos no aplicativo e conforme o formulário, as colorações são critérios de escolhas nas compras solicitadas aos pais. Foi percebido as nuances mais chamativas para o público em questão, sendo a azul como a mais perceptiva e o preto citado como a cor mais preferida pelas crianças, ficando consequentemente apresentado o valor do marketing das cores para o comércio eletrônico.

De acordo com relatos dos participantes, ficou evidente que o mundo da tecnologia está presente no dia a dia das crianças, e o manejo das cores é realizado de forma assertiva quando traz jogos, lojas e vídeos, como os youtubers, comentado nas entrevistas, bem chamativos. Esses meios captam e atraem a percepção infantil de modo a estimularem esse público a convencerem seus responsáveis a comprarem pela internet.

A pesquisa ocorreu de forma não generalizada, visto que foi feita com um público restrito, residentes em uma cidade do interior do Ceará, em Icó. Nisso obtêm-se limitações a respeito do campo vasto deste estudo, mas a amostra trabalhada transmite uma configuração em nível geral mediante a globalização.

A temática trabalhada pode servir como base para pesquisas futuras como: A influência dos youtubers para indução às compras nas crianças; Visão das empresas sobre marketing das cores; Pais versus crianças: qual o mais assíduo em compras via e-commerce? Dentre outras temáticas para essa era da informação.

\section{Referências}

ABREU, L.; VASCONCELLOS, N. Promoção de vendas direcionada para as crianças. 2009. Universidade Federal Fluminense. Disponível em: 
<http://www.uff.br/ensaiosdemarketing/artigos\%20pdf/2/PROMO\%C3\%87\%C3\%83ODEVENDASD IRECIONADAPARAASCRIAN\%C3\%87AS.pdf>. Acesso em: 12 out. 2017.

BARKI, E.; BOTELHO, D.; PARENTE, J. Varejo: desafios e oportunidades em mercados emergentes. Revista de Administração de Empresas, v. 53, n. 6, p. 534-538, 2013.

BATISTA, K. DA S. M..; FERMIANO, M. A. B. Publicidade e criança, uma parceria nada saudável. Revista dos Alunos de Pedagogia. Nova Odessa, SP, v. 1, n. 1, p. 46-59, 2013.

BATTISTELLA, N.; COLOMBO, J. R.; ABREU, K. C. K. A importância da cor nas embalagens como fator influenciador no momento da compra. Biblioteca online de ciências da comunicação, 2010. Disponível em: 〈http://www.bocc.ubi.pt/pag/bocc-kraemer-embalagens.pdf>. Acesso em: 08 set. 2017.

CALAZAES, K. S. V.; FERMIANO, M. A. B. Consumismo e o papel dos pais. Revista dos Alunos de Pedagogia. Nova Odessa, SP, v. 1, n. 1, p. 7-16, 2013.

CARVALHO, H. [Infográfico] A Psicologia das Cores no Marketing e no Dia-a-Dia. set. 2013. Seção Mais Blog. Disponível em: <https://viverdeblog.com/psicologia-das-cores/>. Acesso em: 11 out. 2017.

CERIBELI, H. B.; DE OLIVEIRA, I. R.; FELIPE I. J. DOS S. Um estudo dos determinantes da decisão dos e-consumidores de comprarem no comércio eletrônico. Revista Gestão e Tecnologia, Pedro Leopoldo. Minas Gerais, v. 15, n. 1, p. 174-199, 2015.

DOS SANTOS CLARO, J. A. C.; MENCONI, A. T. L.; LORETO, J. R. Consumo infantil: o telefone celular e a criança. RaUnP. São Paulo, v. 5, n. 1, p 21-32, 2013.

COELHO, L. DA S.; OLIVEIRA, R. C.; ALMÉRI, T. M. O crescimento do e-commercee os problemas que o acompanham: a identificação da oportunidade de melhoria em uma rede de comércio eletrônico na visão do cliente. Revista de Administração do UNISAL. Campinas, v.3, n.3, p. 63-85, 2013. Disponível em: <http://www.revista.unisal.br/sj/index.php/RevAdministracao/article/view/235>. Acesso em: 27 out. 2017.

COGAN, F. B. Influência do ambiente do ponto de venda na compra por impulso de alimentos em supermercados. 2013. 87 f. Trabalho de Conclusão de Curso (Graduação) - Faculdade de Administração, Universidade Federal do Rio Grande do Sul, Porto Alegre, 2013. Disponível em: <http://www.lume.ufrgs.br/handle/10183/87833>. Acesso em: 29 out. 2017.

DO AMARAL, I.; GAMA, M. G.; DA GRAÇA GUEDES, M. Percepção infantil dos logótipos: cores e formas. In: Proceedings of World Congress on Communication and Arts. 2014. p. 125-129. Disponível em: <http://docplayer.com.br/6468872-Percecao-infantil-dos-logotipos-formas.html>. Acesso em: 07 set. 2017.

GIL, A. C. Como elaborar projetos de pesquisa. 5. ed. São Paulo: Atlas, 2017.

GOOGLE PLAY. Super Market Boy Party Shopping. Disponível em: <https://play.google.com/store/apps/details?id=com.kidsfunplus.market.boy.party.shop>. Acesso em: 12 jan. 2018.

_. Shopping Mall Girl. Disponível em: <https://play.google.com/store/apps /details?id=com.cocoplay.shoppinggirl >. Acesso em: 12 jan. 2018.

MARCONI, M. A.; LAKATOS, E. M. Metodologia Científica. 7. ed. São Paulo: Atlas, 2017. 
MARTINS, F. A psicologia das cores aplicada ao e-commerce. 2013. Disponível em: $\langle$ https://www.ecommercebrasil.com.br/artigos/a-psicologia-das-cores-aplicada-ao-e-commerce/>. Acesso em: 28 out. 2017.

MENDES, L. Z. R. E-commerce: origem, desenvolvimento e perspectivas. 2013. $64 \mathrm{f}$. Monografia (Graduação) - Faculdade de Ciências Econômicas, Universidade Federal do Rio Grande do Sul, Porto Alegre, 2013. Disponível em: 〈http://www.lume.ufrgs.br/handle/10183/78391〉. Acesso em: 28 out. 2017.

MOLINA, V. L. I. Construindo projetos de pesquisa científica e social. 1. ed. São Paulo: Biblioteca24horas, 2016.

NOGUEIRA, J. G.; DE ABREU, J. A. P.; PAIXÃO, C. H. E S.; DE OLIVEIRA, R. C. A embalagem como componente estratégico do marketing para lançamento do produto. CPMark - Caderno Profissional de Marketing - UNIMEP. São Paulo, v. 3, n. 1, p. 60-73, 2015. Disponível em: < http://www.cadernomarketingunimep.com.br/ojs/ index.php/cadprofmkt/article/view/39/45>. Acesso em: 29 out. 2017.

REDAÇÃO. Crianças arriscam-se demais na internet, aponta estudo. Revista Exame, maio. 2013. Sessão Tecnologia. Disponível em: <https://exame.abril.com.br/tecnologia/comportamento-de-riscona-web-comecaria-na-infancia/\#>. Acesso em: 03 out. 2017.

RIBEIRO, M. V. A cor no processo criativo de ações de comunicação interna e de endomarketing. 2014. 99 f. Trabalho de Conclusão de Curso (Graduação) - Faculdade de Habilitação Publicidade e Propaganda, Universidade Federal do Rio Grande do Sul, Porto Alegre, 2014. Disponível em: < http://www.lume.ufrgs.br/handle/10183/110372?locale-attribute=es>. Acesso em: 04 nov. 2017.

SILVA, M. V.; FERMIANO, M. A. B. Consumo e o universo infantil. Revista dos Alunos de Pedagogia. Nova Odessa, SP, v. 1, n. 1, p. 253-262, 2013.

VENDA, A. Método Quase-Experimental. Disponível em: <https://prezi.com/wszubkktmkz9/metodo-quase-experimental/>. Acesso em: 12 nov. 2017.

\section{Como citar este artigo (Formato ABNT):}

ANGELIM, Bruna Martins; OLIVEIRA, Alyne Leite de; ROLIM, Tulio Vidal; VIANA, Hudson Josino; ALENCAR, Maria Patrícia de. O Impacto das Cores em Crianças na Aquisição de Produtos via ECommerce. Id on Line Revista Multidisciplinar e de Psicologia, 2018, vol.12, n.40, p.956979. ISSN: 1981-1179.

Recebido: 26.05.2018

Aceito: 28.05 .2018 